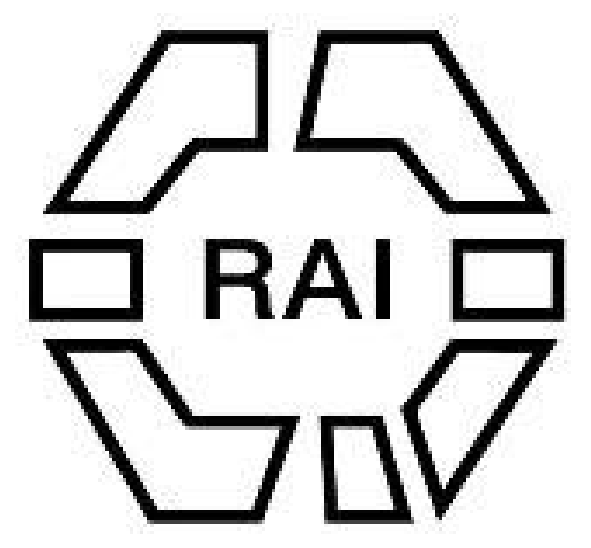

\title{
WILEY
}

\section{Notes on Some Native Medicines from Southern India.}

Author(s): Albert Gille

Source: Man, Vol. 6 (1906), pp. 182-187

Published by: Royal Anthropological Institute of Great Britain and Ireland

Stable URL: http://www.jstor.org/stable/2787251

Accessed: 27-06-2016 10:49 UTC

Your use of the JSTOR archive indicates your acceptance of the Terms \& Conditions of Use, available at

http://about.jstor.org/terms

JSTOR is a not-for-profit service that helps scholars, researchers, and students discover, use, and build upon a wide range of content in a trusted digital archive. We use information technology and tools to increase productivity and facilitate new forms of scholarship. For more information about JSTOR, please contact support@jstor.org.

Royal Anthropological Institute of Great Britain and Ireland, Wiley are collaborating with JSTOR to digitize, preserve and extend access to Man 
(IV.) M. Van Gennep appears to think that Australian tribes were more probably evolved "par convergence" than "par segmentations dichotomiques." That this was so is the position which I myself defend. But I deem it infinitely more probable that the Arunta, with their confessedly advancell organisation, have lost the names of the earliest converging bodies, the phratries, than that they "perhaps have not yet created" these names. The phratry names are always found in the lowest and most simple, but tend to disappear in the higher and more complex, organisations. It is well known that phratries "in our sense" have vanished among American tribes which once possessed them (cf. Frazer, Totemism, p. 61, citing Morgan, Ancient Society). The "classes" are, by general agreement.(if that goes for anything), later than the phratries, and, as they do the phratries' work, and more, the tendency, in Australia, is for the phratry names to be forgotten. Therefore, the opinion that the Arunta, with eight classes, "may perhaps not yet have created phratries" appears "singular."

(V.) As to the correct or erroneous nature of my own opinion about "the " conceptionist theory of Australian totemism," no doubt the truth will come out in the course of time and of discussion. Securus judicat orbis terrarum.

Moved by the cavalier usage which M. Van Gennep has bestowed on Mr. Atkinson's work, I have again read all through it. I see nothing which can justify the statement that Mr. Atkinson found the origin of marriage prohibitions in "instinct" or "innate" sentiment. He represents what we call incestuous unions as originally prevalent in a brutal and semi-brutal stage. No "instinct" prohibited them. Prohibitions were successively introduced, he says, in obedience to "ideas" (p. 212), to "intelligence" (p. 228), to "intelligent acceptance by the intruding junior of the " sole right of the senior" (p. 235). To meet each new situation there "was " inevitably the continuous evolution of law" (p. 248). On Mr. Atkinson's theory, each stage of law, except that prohibiting unions of father and daughter, left its trace in an "avoidunce" still imposed by customary law. Yet M. Van Gennep still says that to formulate Mr. Atkinson's system is "se contenter 'd'une explication " de sauvage." I remain "astonished" hy the criticism. Mr. Atkinson never says that "avoidances" are produced by "horror"; and he denies that, in his experience, "horror" is produced by "avoidance." A. LANG.

India, South.

Gille.

Notes on some Native Medicines from Southern India. By the Rev. Albert Gille, S.J. Communicated by the Stonyhurst Anthropological 113 Bureau through the Secretary.

Brahma sent disease on to the earth as a punishment for sin, a disease for each sin ; but afterwards he gave to man the science and knowledge necessary to cure them. So he devised the science of medicine (Aiur weddam), and informed Siva, who spoke of it to the Dewas (demi-gods). The Dewas came down to earth to teach medical science to the Ashwini mahagrishi (holy sages), who wrote down the teaching "very exactly and very correctly."

Bile (Pittam).-This disease appears to be prevalent in Malabar, and apparently is caused by eating rice and vegetables.

A jam-like substance called lehim, consisting of a decoction of tamarind leaf and iron, is boiled for a fortnight or so, when purana pittam is added. This latter ingredient consists of a kind of iron ore, heated red-hot, and dipped in cow urine. This process is repeated for eight days when the iron is reduced to powder and added to the first decoction.

Another remedy is to make a mixture of coconut milk, cut-up bananas, lime, ginger, \&c. These various ingredients are put in a vessel, which is carefully closed, and 
boiled for two hours. The vessel is then kept near the hearth for eight days so as to keep the mixture warm.

Borls.-1. Mix shell lime with water. When the water has become clear, add ginger-oil to half of it and shake. The mixture then becomes an ointment and is put on the boil.

2. Mix powdered magnal with castor-oil, and place pieces of cloth dipped in the mixture on the boil.

3. Cut off the end of a bunch of poowanwara (a kind of plantain), open the flower, and cut it into five pieces. Mix this in four bottles of water and drink it with honey. This medicine acts as a preventive.

Bruises, Internal.-The root of kandari and the tender leaf of the areca nut are mashed together, mixed with human urine and druuk. This is a very secret medicine.

Consumption, Chest Disease, Coughing (Rajah Eshmau).-These diseases are rare and are considered as hereditary. When they occur they are treated in the following ways : A decoction of araka or sealing wax is made, which reddens the water while it boils. With twelve ounces of this are mixed two bottles of water and, after sugar has been added, the mixture is given to the patient. If this remedy is not efficient, a jam-like substance (lehim) is made of boiled mutton, mixed with several powders, candy sugar, ordinary sugar, \&c. All these are mixed together and boiled.

While undergoing this trentment the patient is not allowed to eat fish, coconut, or any sour food. He must remain at home and avoid the sun. The treatment lasts for fourteen days, and, after the treatment, the same number of days has to be passed at home.

Brahmins, instead of this, sleep with a living rabbit on their chests, but some prepare the lehim with rabbit instead of mutton.

Coughing in children (Nelankara chuma).-Make a mixture of ambrosia, rice, and jaggari (sugar from toddy) and put it on the floor. The child has to lick it while it is on the floor. Mix together twelve heads of kari (black fish), half the quantity of pippali and dry ginger, and powder the mixture. To be given with honey and sugar. Powder and mix together the leaves of kuni (a creeper) and rice and take with jaggari.

Yangal, a kind of asthma.-In four bottles of water boil $1 \mathrm{lb}$. of small bat's flesh, until only one bottle of liquid remains. Add to this cardamom seeds, dry ginger, pippalli, powdered kwolawere, and mix with $\frac{1}{2} \mathrm{lb}$. of ghee. Boil again until a hard deposit is formed. This must be separated from the liquid and kept for a day. Half a rupee's weight must be taken every day, and the patient must abstain from fish, tamarind, and buttermilk, and stay in his room.

Dog BITE.-Burning firewood is held over the wound and water is poured over the fire so as to flow on to the bite. Then the tender leaf of the pepper plant is mashed, salted, and put on the wound, being tied down with an areca leaf.

Drsentery.-Cover karanjikuru seed with cow-dung and heat in the fire. As soon as the dung is dried up the seed is broken open, the cotyledon taken off, powdered, and mixed with toddy. This has to be drunk for three days.

Another remedy is to cut open a large banana and insert two grains of opium under the skin. The fruit is then covered with a plantain leaf and dried in the fire.

Another cure is to eat, in the morning, ducks' eggs which were boiled the evening before and kept in mud during the night; while still another medicine is to make a powder of the tender leaf of the karanjee tree, opium, and soft mango, all of which have been dried previously. 
Eye Diseases.-Anticurudu (night blindness).-Eat the lungs of the crow after boiling them, or go and beg at eight houses during the night and eat whatever is given you.

Chingar (sore eyes).-Wash the eyes with a mixture of the mashed flower and tender leaves of St. Anthony's flower and mother's milk, or with a mixture of mowil chewian (a plant), jiragana (a seed), and mother's milk.

Padalam (red eyes).-Mash thirty-two buds of the chetti flower with thirty-two jiragam seeds. Dip it in mother's milk and wash the eyes with it.

For eye diseases that are difficult to cure, pour oil, preferably nasian, up the nose.

For a boil in the corner of the eye, rub the eyes either with black pepper rubbed with mother's milk against a stone or with the tender leaf of kakakori (a creeper), mashed jiragam, and mother's milk.

For a fly in the eye walk backwards eight or ten feet. To get clear eyes eat ants' eggs.

Another medicine is the following :-Kentenda Lawanam. A hen with a black skin is killed when it is on the point of laying its first egg. Its blood must not be shed. It is then plucked and cut open. Its heart and lungs are taken out and after being mixed with powders are put back in the body, which is then covered with a special unguent and put, with roots, leaves, \&c., into a chetty, or earthen vessel, half filled with water. The vessel is covered with a cloth and boiled for six hours, from 6 a.m. till noon. The bones are then removed and the carcase, after being dried in the sun for two or three days, is ground iuto a fine powder. This is then mixed with honey and swallowed.

Fever.-The rajah of all the diseases is fever (Yoro roga padi papma). It was first sent by Siva as a punishment to some persons who rebelled against him. $\mathrm{He}$ opened that one of his three eyes which contains fire, and sent the fire of fever to the earth.

There are in the body three doshams or germs called Wada juram, Pitta juram, and Kappa juram. When a person is in good health these doshams are present in equal quantities, but, if any of them increase or diminish, equilibrium is upset and fever supervenes. Wada is the germ of rheumatism, Kappa of fatness, and Pittam of bile. During the day from 6 to 10 a.m. kappam is in the ascendant, from 10 to 2 p.m. pittam, which causes temper, and from 2 to 6 wadam, which causes calmness. During life from infancy to the age of 30, kappam is the most prominent germ, from 30 to 60 pittam, and from 60 onwards wadam. The medicines prescribed depend upon these seasons.

There are three kinds of fever, Sapta juram, a slight fever lasting for seven days, Nawa juram, lasting for nine days, and Dwidicham which lasts for twelve days. If a fever is not cured in twelve days it will last for twenty-one days, if it is not cured by then it will last for thirty-two days, and then for ninety days. This is the worst fever.

As soon as a fever appears the sick person is deprived of food for three days, and the only drink allowed is a decoction of four ounces of dry ginger and eight ounces of coriander seed (kwotummali). It is only on the lapse of these three days that the proper treatment begins. The patient then receives a mixture of red onion (tolassi) leaf, three times a day. The leaf is made into a small bundle wrapped up in cloth. This is warmed, dipped in water and squeezed into the patient's eyes. A patch, the size of a rupee, is shaved on the top of the head and covered twice a day with ointment. The patient also has to drink kanji six times a day.

If a doctor is necessary he should be sent for in the moruing, and should not be summoned for the first time on a Friday. The person who calls the doctor must not mention the sickness before the name of the patient, or he will die. The doctor, 
unless he happens to be a Christian, is always an augur. If on his way to the patient's house he sees a cat cross the road, or meets a man carrying a broomstick, or a woman with a fan, he will not go on, but if he meets a brabmin or a cow or bull with a loose rope it is a good sign. The doctor carries his medicines in a metal box, while a servant carries another box made of brass.

The doctor has to examine the patient in three ways, called Derishanal, looking over the body; Sparishanal, touching the body; and Spresne, asking questions. He then has to examine the body in eight different places (Ashtastana paretshan) :eyes, tongue, teeth, palm, \&c. He then takes a palm-leaf and prescribes the first decoction, which is made of dry ginger, dewadaram, coriander seed, cheruwarudina and wel warudina. Should this not cure the fever the doctor changes his prescription every day.

To find out how long the disease will last, or if it will be cured, the doctor examines the urine (Motra parecha), but he only does this when the sickness is very dangerous. The urine has to be taken early in the morning and sent to the doctor before sunrise. The doctor pours it into a vessel and with a blade of grass lets fall a drop of ginger oil into the urine.

If the drop does not spread the patient will die.

If it spreads well the sickness can be cured and the patient will live long.

If it spreads very little, forming a hole in the centre, the patient will die.

If the spreading oil takes the form of a leech or a snake the sickness will be difficult to cure.

If the drop spreads in the form of a lion, the sickness can be cured, but only with great difficulty.

If it spreads in the shape of a wolf, little hope is left.

If it spreads in the shape of an elephant, the sicknoss will take a long time to cure, but death will not follow.

The operation has to be carried out in the greatest secrecy, and the doctor must not talk to anyone about it.

When the patient is cured, a special day, either a Werlnesday or Saturday, is chosen, according to the moon, for him to take his first bath. On the day before the water is boiled and mixed with medicine. The day itself is a feast day, doctor and relatives all being invited to be present. The doctor, with great ceremony, pours the water over the patient's head. 'The doctor, if he belongs to the same caste as the patient's family, dines with them; if not he goes home, after receiving a new cloth and money wrapped up in betel leaf. On the second and third days the patient is oiled with the same ceremonial. Lastly, a priestess comes to purify the house and the patient's room. It is always a female who does this work.

Headache.-Deshamala Nawanidam (Suria ourtam).-This headache begins at sunrise, increases in intensity till noon, when it begins to lessen, finally disappearing at sunset.

A decoction of ten different plants and four bottles of cow's milk is boiled till the water evaporates, and the milk alone remains. After this has been kept for a day it is made into butter, which is put on the patient's head, part of the hair having been shaved off previously.

Another remedy for headache is to pour hot fowl's blood into the nose. This remedy, however, has its dangers in the case of a pregnant woman, as the blood may run into her head and canse death. This result may be prevented by cutting a fowl into two parts and covering the head with them. If this is done before the blood reaches the head the patient can be saved.

Other remedies against headache are to cut powdered bellacaruga (grass), cottam root, dry ginger, and red sandalwood on the forehead : to pour dry ginger powdered 
in woman's milk or cold water into the nose, and to dip the point of a needle in pepper, hold it for a moment in the fire, and then breathe the pepper in through the nose.

Indigestion (caused by eating Jack fruit).-Burn the dry stem of a coconut; mix the ashes with water, and, when they have formed a deposit, drink the water.

INSANITY.- - 1. Put mashed leaves of brami on the patient's head every morning and evening.

2. Make a decoction of dry gooseberry, ramasham and tetamparal (a seed) and pour it slowly and continuously over the patient's head.

3. Put a mixture of fresh butter and mashed willila (white and green leaves) on the patient's head.

4. Make a small hole in a ripe lemon and put into it ripe black pepper soaked in cow's milk. Hang the lemon near the fire for forty-one days. Then remove the skin from the pepper and rub the seed, with woman's milk, against a stone. Rub the eye inside the eyelid with the stone.

Purples.-Remove the skin of a tender red coconut and insert in it a pill. Cover the nut with a tender coconut leaf. Next stretch sticks over a vessel half filled with water and lay the nut on the sticks so that it cannot touch the water. Boil the water and steam the nut for three hours. Next mix cardamom and cloves with the coconut water, and dip in the mixture a piece of gold which has previously been rubbed against a stone. This mixture of liquid and powdered gold has then to be thrown into the coconut water, which has then to be drunk.

Rheumatism (Chira bala).-The natives recognise eighty different kinds of rheumatism, among which is numbered leprosy. The skin is to be rubbed with an oil made of $4 \mathrm{lbs}$. of the root of kurundorti (malay alam), dissolved in four bottles of milk and one bottle of ginger oil. The mixture has to be filtered every day for twenty-one days, each time four bottles of milk being added. A rupee's weight of this is also to be eaten every day, as long as the patient can afford it.

Skin Diseases.--Sores : On the Legs.- The shell of the black tortoise (karana) is burned and powdered, mixed with saffron, and put on the sore place.

Maroti kuru (oil seed) half burned, the same quantity of turushe, wax, and tender leaf of kalasham, are mashed together and applied to the sore.

On the Body.-Drink a decoction of pawo (a root from China) with sugar, or eat the pawo, mixed with sugar or honey. The sufferer is not allowed to eat fish, coconut, tamarind, or buttermilk.

Andawadam, a disease in which the skin from the stomach to the knee peels off. Mix turushe with white of egg and rub the body with it.

Ringworm.-Pimples appear on the skin in the form of a spiral.

Dip a pin in kashu nut oil and rub it lightly over the itching spot; or mash kokomaram leaf, mix it with rice water, and rub it over the body.

The Itch.-(1) Crush the inside of the Kalli fruit and mix it with the juice of the leaves. This must then be mixed with ginger oil and rubbed over the body. (2) Powder together sealing wax, sulphur, white salt (indoopo), amoukiram, and the skin of the kaduka seed, mix this powder with the milk of a ripe coconut. When no water remains in the milk, rub the body with the mixture for three days. (3) Make an oil called pinnataklam. Take the bark of four different kinds of banyan trees (Atti, Itti, Araya, and Peral), dry them, cut them into small pieces, and boil for three hours a day for three or four days. When the liquid becomes red, separate the deposit, powder it, and mix it with red sandalwood, makkipoo, and karaiampow. This mixture must then be added to the liquid. Four bottles of this added to a half bottle of ginger oil, a quarter bottle of ghee, and a quarter bottle of woretena, [ 186 ] 
will give after boiling one bottle of pennataklan. Remove the deposit, when it becomes like wax. Rub the oil on the body, but not on the head.

Small-pox.-CThere are eighteen different kinds of small-pox, produced by eighteen different evil spirits. Four of the varieties are the following:-

Agamaral causes death after six days; atter death small boils appear. There is no medicine that can cure it.

Kanaga (gold) kaluri.-The body becomes golden, and if the sufferer recovers he will become a king.

Palkaluri.-A smell of milk comes from the body, which attracts snakes.

Annalli (name of a snake).-The patient acts like a snake, hissing and moving his tongue and hands like a snake. It is considered a disgrace to die of this variety of the disease, and the burial takes place during the night without any ceremonies.

As soon as a case of small-pox develops in a house the whole family leaves, and the patient is left in the care of one who has himself had the disease and who indulges in strong drink to keep off the devils. The first medicine given is a decoction of dry ginger and kotomali, but when the rash begins to appear a decoction of the bark of ariwapo, dry ginger, and karuka seed is substituted.

Should the patient die the corpse is buried in the same place where the death took place, and three days afterwards the homom is held, when the house is purified by a sorcerer.

Stomach Ache (Naligara Lawanam).-The milk is drawn out of a ripe coconut, which is then filled with salt and various powders, and the hole carefully shut. The nut is then covered with mud and roasted in the fire for a night. In the morning it is broken, dried in the sun, and ground into a powder, which is mixed with honey, and given to the patient.

Toothache.- - Lay the seed of chunda on a red-hot iron with a few drops of oil. The sufferer inhales the smoke through a coconut shell, with a hole at the top.

Rub the gum with a mixture of opium and camphor.

Voniting.-Put on the chest a mixture of water and powdered white sandalwood, or drink the juice of a pomegranate mixed with honey and powdered cardamom.

Worms (Shula).-Children may have two kinds of worms, a short one and a long one. The origin of the disease was a sin that made Vishnu very angry, so he threw his trishulam (sceptre with three points) on to the earth, and from the place where it struck sprang the shula. There are many treatments for this complaint.

Boil in water for two hours $1 \mathrm{oz}$. of mercury and $1 \mathrm{oz}$. of agnanam. Keep the vessel near the fire for twelve days. Early in the moruing the child has to drink a tumbler of the decoction mixed with sugar.

For worms that live in the stomach and come out through the nose, mix tumba with onion, put it in a cloth and smell it. If the worm comes to the eyes the person will die.

To kill the worm, make seven rings of seven tender ribs of coconut leaf (ikel). Make a decoction of these, three earth worms, 12 grains of cardamom, dry ginger, and the withered flowers of tumbakoodam.

ALBERT GILLE.

\section{Religion.}

\section{REVIEWS.}

Adonis, Attis, Osiris: Studies in the History of Oriental Religion. By 114
G. Frazer, D.C.L., \&c. London : Macmillan, 1906. Pp. xvi + 339. Price 10s.

This book is, from the literary point of view, a masterpiece. It has all the lucidity and charm of style we expect from Dr. Frazer. And it hangs together; has unity. Here and there we wander off on some seductive side-path (volcanic religion, 